\title{
La autoridad de los que sufren*
}

\section{Martha Zechmeister, C.J., Centro de Reflexión Teológica, San Salvador}

\section{De la potestad opresora a la autoridad liberadora}

Haciendo una abstracción y simplificación casi insuperable, se puede afirmar de una manera general que hay dos tipos de gobierno, de ejercicio del liderazgo, independientemente de su contexto, sea este político o eclesial, familiar o público. Estos dos tipos de gobierno se pueden caracterizar con dos palabras que tienen su origen en la política romana: "potestas", poder, por un lado, y "auctoritas", autoridad, por otro.

El primer tipo, caracterizado como potestad, se construye sobre una desigualdad, una asimetría. Quien tiene poder, tiene una ventaja sobre los demás. La ventaja puede tener su fundamento en un mayor conocimiento, en una acumulación de recursos económicos o en el ejercicio de la violencia física, psíquica o social. El sociólogo Max Weber ha definido el poder con estas palabras clásicas: "El poder significa cualquier oportunidad de imponer la propia voluntad, dentro de una relación social, aun contra toda resistencia y cualquiera que sea el fundamento de esa oportunidad". El poderoso, el potente, es capaz de mantener bajo control su esfera de dominio. Dispone de los medios para imponerse a sus súbditos, para quebrar cualquier resistencia y, en el peor de los casos, para destruir a los que no se le sometan.

El segundo tipo de liderazgo, caracterizado como autoridad, también incluye una asimetría. También una persona con autoridad tiene una ventaja con relación a las demás. Sin embargo, el modo de relación entre una persona con autoridad y las personas que respetan esa autoridad es fundamentalmente diferente. No se define por imposición y sumisión, sino que se basa esencialmente en un reconocimiento libre y mutuo. En esta relación, la "asimetría" en experiencia,

* Conferencia en la Asamblea General de la UISG (Unión Internacional de Superiores Generales) en Roma, del 3 al 7 de mayo de 2013.

1. M. Weber, Economía y sociedad. Esbozo de sociología comprensiva, México, 1944, p. 43. 
conocimiento, posición social o recursos, no elimina la igualdad fundamental entre las dos partes que están en relación. Más aún, la autoridad nunca niega una fraternidad fundamental que no permite alzarse sobre otras personas. Se puede "tomar el poder", pero nunca se puede "tomar la autoridad". La persona que la "tiene" se la debe a la afirmación gratuita y adulta de las personas que la reconocen. Jamás se convierte en una "posesión que no se puede perder", pues hay que merecerla y recibirla siempre de nuevo. La autoridad se destruye a sí misma en el momento en que recae en la violencia. Imposición y autoridad son esencialmente incompatibles.

Renunciar a la imposición para nada es sinónimo de pérdida de la autoridad o de su autosupresión. Esta renuncia tampoco tiene que ver con la debilidad, ni con una concepción "antiautoritaria" o de "laissez faire". La condición de la verdadera autoridad se puede aplicar más bien a personajes de gran vigor. Su fortaleza y energía interior, sin embargo, no son usadas para mantener a los demás en un estado de dependencia infantil, sino para facilitar su crecimiento integral: su desarrollo humano, social, político, espiritual.

"Autoridad liberadora" no es ni mucho menos sinónimo de anarquía. Ejercer este modo de autoridad exige todas las energías vitales para crear y proteger con firmeza espacios sociales que hacen florecer la vida, que permiten el desarrollo de personas y de comunidades que se caracterizan por relaciones libres y respetuosas. Las Constituciones de la Compañía de Jesús, que son también las constituciones de mi congregación, dicen: "El Prepósito General tenga total autoridad sobre la Compañía ad aedificationem (para edificar)" ${ }^{2}$. Con la autoridad hay que proteger a los indefensos de los abusadores y explotadores dentro y fuera de la comunidad, sin caer por eso en la trampa del paternalismo o maternalismo. Es la tragedia de los sistemas autoritarios: las personas oprimidas tratan de sentirse poderosas oprimiendo a otras todavía más débiles. (Esa es, a mi parecer, una de las trágicas raíces del escándalo de los abusos sexuales y maltratos físicos cometidos por sacerdotes, religiosos y religiosas.)

Personas con verdadera autoridad no se preocupan en absoluto por preservar el propio poder, sino que, por el contrario, están movidas por el deseo de que otras personas crezcan en autodeterminación y en libertad de acción. La verdadera autoridad crece en la medida en que hace crecer a otros y otras: Jesús libera a la mujer encorvada por el demonio que la aplasta, y la defiende de las autoridades que quieren impedir su sanación remitiéndola a la ley ritual, y así pone en riesgo su propia vida. Usa su libertad y vigorosa autoridad para "empoderarla", para que ella se pueda enderezar por sus propias fuerzas. Le devuelve su dignidad humana, la libera para andar erguida y libre (cfr. Lc 13, 10-17).

2. Constituciones de la Compañía de Jesús, n. 736 . 


\section{Aplicación ad intra}

Lo dicho hasta ahora puede darse por sobreentendido. En las últimas décadas, ciertamente, por lo que toca al ejercicio de la autoridad, las congregaciones religiosas han cambiado su discurso, y no cabe duda de que hay mucha buena voluntad de ponerlo en práctica. Sin embargo, todavía hay bastante inquietud sobre la realidad del día a día. ¿Se puede dar por supuesto que las superioras y formadoras buscan con autoridad que cada hermana - desde la novicia hasta la anciana - pueda desarrollarse "como Dios lo ha pensado"? ¿O no ocurre con demasiada frecuencia que los "procesos de formación" (tanto inicial como permanente) todavía se parecen más a un "lecho de Procusto"? (Procusto era un personaje malvado de la mitología griega, que ofrecía posada a viajeros solitarios. Si la víctima era alta y su cuerpo más largo que la cama, cortaba las partes de su cuerpo que sobresalían. Si por el contrario era más pequeño, lo estiraba a la fuerza. Así, "la cama de Procusto" es la metáfora para un estándar arbitrario para forzar una conformidad exacta.) ¿No sigue siendo todavía una preocupación dominante que las personas "encajen", en vez de acompañarlas en la aventura fascinante de que cada una se encuentre con su misterio y que pueda desarrollarse en plenitud? ¿No domina muchas veces todavía el miedo a personajes que destacan más allá de lo común? "Se corta lo que sobresale", reza un dicho alemán.

Una variación especialmente triste del "lecho de Procusto" fue la "formación" de religiosas africanas, indias o latinoamericanas por fundaciones europeas. En nombre de la formación religiosa se destruía sus patrones culturales y se las sometía a una europeización violenta. Así se mutilaba seriamente a personas humanas que quedaron separadas de las fuentes profundas de su vitalidad y creatividad. ¿Ha quedado superada, en lo más hondo y en verdad, la arrogancia del eurocentrismo y su manía de superioridad? ¿En verdad hemos renunciado las europeas a la "soberanía de interpretación" de lo que es y de lo que tiene que ser la vida religiosa? ¿Podemos aceptar y respetar serenamente la des-europeización y la riqueza del pluralismo cultural: la pluralidad sobre cómo vivir en comunidad, cómo realizar la misión y cómo expresar nuestra relación con Dios?

Preguntas semejantes se imponen por lo que toca al modo de vivir las relaciones humanas en las congregaciones. En el discurso, ciertamente hemos superado el modelo jerárquico-vertical, centrado en la superiora que controla todas las relaciones de las hermanas, dentro de la comunidad y mucho más fuera de ella. Sin embargo, los patrones, sufridos e internalizados durante siglos, siguen actuando inconscientemente, y por eso de forma más sutil. ¿De verdad los procesos de formación se han liberado del modelo de la dependencia y del control, o siguen todavía, escondidamente, con su obra destructora? ¿De verdad promueven y facilitan el desarrollo de relaciones adultas y reconocen el valor imprescindible de la amistad - entre las hermanas y con las personas a quienes queremos servir-? Un abismo separa la sintonía y la vivacidad entre personas 
adultas y maduras en su identidad, de la uniformidad. Por último, una comunidad configurada por el control y la uniformidad no sirve para su misión evangélica. El único modelo de comunidad que nos compromete es el movimiento de Jesús: sencillo, fraterno, y con gran calor humano para acoger y compartir la vida con todos los excluidos del banquete de los ricos y poderosos.

\section{Aplicación ad extra}

Estas dos concepciones de liderazgo también se pueden ilustrar desde la "meditación de las dos banderas" en los Ejercicios espirituales de Ignacio de Loyola. Él nos invita a un ejercicio de imaginación: plantearnos dos líderes opuestos, Cristo y Lucifer. Hace un perfil de dos modos de señorío, abismalmente diferentes, con metáforas fuertes y primitivas: Lucifer, el "enemigo mortal de la naturaleza humana", se encuentra asentado en Babilonia "en una grande cátedra de fuego y humo, en figura horrible y espantosa". Es una impactante manifestación de poder que fascina, y a la vez provoca como primera reacción, casi inevitablemente, sumisión y servilismo. Es un poder basado en el temor. Lucifer enseña a sus demonios una táctica sutil de seducción. Les manda que primero despierten en sus seguidores la codicia de riquezas y en consecuencia los empujen hacia el ansia del honor y la soberbia. Su truco genial es que seduce con la ficción de que los que se someten a su dominio van a subir en dominio y prestigio. Pero la verdad es que toda la dinámica desemboca en un sistema de dependencia, que acaba con toda autodeterminación y somete de manera brutal. Al final, los victimarios y las víctimas se hallan atrapados en las mismas "redes y cadenas".

Es obvia la aplicación de estas metáforas primitivas a los poderes que hoy dominan en gran parte del mundo. La industria del armamento, las bolsas y agencias de rating con sus liturgias y símbolos bombásticos de poderío, condenan a innumerables seres humanos a la miseria. Al igual que los demonios, los sujetos que actúan, los usureros y lobbyistas, no tienen rostro, quedan ocultos detrás de la fachada engañosa, detrás del "fuego y humo".

La otra bandera, el otro líder que Ignacio nos presenta, es Cristo nuestro Señor, asentado en Jerusalén, un "lugar humilde, hermoso y gracioso". Nada de demostración de poder, sino invitación a la pobreza y a la humildad. Ignacio nos confronta con la paradoja de que Cristo "conquista" (entre comillas) todo el mundo con la renuncia radical a toda violencia e imposición, e invita a sus seguidores a acompañarlo en el mismo camino. El motor del mundo, en los tiempos de Ignacio de Loyola, así como hoy día, es la codicia para acumular riquezas, capitales. $\mathrm{Y}$ el prestigio que gana una persona, una comunidad, un grupo social, se mide por la cantidad de lo acumulado. Quien no se somete a esta lógica hace el ridículo y sufre impotencia. Que Cristo invite a la pobreza y a la humildad quiere decir que invita a "revertir el rumbo" de la lógica del mundo de una manera radical. Ignacio Ellacuría dice en un discurso que dio en Barcelona el 
6 de noviembre de 1989, 10 días antes de su asesinato: "Solo utópica y esperanzadamente puede uno creer y tener ánimos para intentar con todos los pobres y oprimidos del mundo revertir la historia, subvertirla y lanzarla en otra dirección". La humildad no es un deseo perverso y autodestructivo, sino el valor y la libertad de vivir radicalmente de modo "contracultural", así como la disposición para asumir las consecuencias con sencillez. Desenmascarar las redes de dependencia, descubrir los juegos de imposición, del afán de lucro y del servilismo, molesta a los intereses de los "potentes" y por eso arrastra a la persecución y la cruz. Sin embargo, solo con los que se arriesgan en el camino de Jesús puede irrumpir el Reino de Dios en este mundo real, y solo así pueden humanizarse las relaciones entre los seres humanos.

Es obvio que el moho de la "lógica del mundo" e mete también en todos los estratos de la Iglesia, así como en las comunidades de religiosos y religiosas. También en nuestras comunidades vivimos en una lucha permanente entre "los dos reinos", entre "las dos banderas". Por eso, para ejercer "autoridad" dentro y fuera de la Iglesia, hacen falta personas que hayan integrado todas sus energías vitales y agresivas y sean capaces de usarlas libremente para la batalla inevitable. La motivación que las empuja ciertamente no es la ambición de poder, sino su pasión por la vida, la pasión por las víctimas del poder, que es la pasión del mismo Dios. Hacen falta ojos limpios y un corazón puro y honrado para descubrir y denunciar con valor las estructuras, y las personas que se esconden detrás de ellas, que someten y explotan a otras personas económica, emocional y socialmente.

Jesús es la "autoridad liberadora" encarnada y su modo de "gobernar" es el arquetipo y "el canon", la medida normativa, de toda autoridad legítima en la Iglesia. Sin embargo, ya en los primeros siglos del cristianismo el modelo judío patriarcal comenzó a desplazar al estilo jesuánico. ¡Qué diferencia entre la autoridad de Jesús y el buen patriarca de las cartas pastorales! De un lado, Jesús, que empodera a los pequeños y marginados y que mantiene relaciones fraternales e igualitarias con las mujeres. Por eso desafía a los sacerdotes y los ancianos del pueblo y se enfrenta con libertad total con Pilato, el representante del Imperio romano, que tiene el poder para torturarlo y matarlo. Y del otro lado, como modelo ya de la autoridad eclesial incipiente, el buen padre de familia "que gobierna bien su propia casa y mantiene sumisos a sus hijos con toda dignidad" $(1 \mathrm{Tim} 3,4)$. Perdonen mi pregunta, que puede parecer ingenua o maliciosa, pero que es totalmente sincera: ¿Cómo fue posible que la Iglesia se haya distanciado tan rápidamente de las palabras de Jesús: "Todos ustedes son hermanos. En la tierra a nadie llamen padre, pues uno solo es su Padre, el del cielo" (Mt 23, 8s)?

Sabemos muy bien que las cosas se complicaron mucho más cuando la Iglesia dejó de ser una minoría perseguida en el siglo IV y se convirtió en una Iglesia del Imperio romano, participando en su poder y apoyándolo. La autoridad evangélica 
se convirtió en "potestas sacra", en "poder sagrado". La comunidad de los cristianos dejaba de ser una Iglesia martirial en seguimiento de Jesús, el protomártir, dando su vida por la defensa de las víctimas. Cada vez más, la misma Iglesia se convirtió en parte de un mundo que produce víctimas, o al menos las tolera, como "daño colateral". La simbiosis entre poder político y poder eclesial arrastraba el serio peligro de que la Iglesia traicionara su propia esencia, su misión, que llegara a perder su autoridad, que tiene su único fundamento en Jesús y en el Evangelio, y se transformara en una institución poderosa que ante todo defiende sus propios intereses. Sin embargo, desde su origen como comunidad de Jesús, la Iglesia tiene un único derecho de existir: hacer presente - con autoridad jesuánica - el Evangelio como realidad salvadora y liberadora en las realidades que afligen y esclavizan a los seres humanos en este mundo.

\section{La silla vacía}

Para la tradición católica, el concepto de "representación" es esencial en su manera de entender la autoridad en la Iglesia. Un eco de ello se encuentra en las reglas y constituciones de las órdenes y congregaciones. Las Constituciones de la Compañía de Jesús hablan con mucha naturalidad del papa como "vicario de Cristo nuestro Señor" y del superior como el "que está en lugar de Cristo nuestro Señor". ¿De verdad puede alguien "sustituir", "representar", "estar en lugar" de Cristo, del "Mesías"? ¿Y puede ocurrir eso como "opus operatum", no por la autoridad o el carisma que corresponde a una persona, sino por un cargo asignado? ¿Se puede de verdad "institucionalizar" la autoridad liberadora de Jesús? ¿Se puede "representar" la autoridad de Dios en este mundo contingente y relativo?

Se podrá dar por sobreentendido que, ciertamente, eso no puede ser pensado al modo de los faraones, de los emperadores y césares, como apoteosis que coloca a una figura histórica entre los dioses, ni tampoco al modo de los líderes y caudillos que "por gracia de Dios" subyugan a los pueblos. En el transcurso de la modernidad, la Iglesia y la teología han aprendido en un doloroso proceso que no se puede aplicar este modelo al gobierno eclesial y que no está permitido fusionar la autoridad espiritual con el poder político. Y aunque muy tarde, el Vaticano II nos enseñó que tampoco se puede entender la "representación" como concepto antidemocrático, que niega la dignidad del pueblo y perpetúa la construcción del poder desde arriba.

¿Pero en qué consiste en definitiva el sentido auténtico de "representación", de "vicario de Cristo en la tierra", de "en lugar de Cristo"? En verdad el poder eclesial y espiritual en lo más profundo es una paradoja, que solamente existe en su continua superación. Traiciona su propia esencia y vocación en el mismo momento en que "toma" el poder, en que se instala en el poder como los potentados de este mundo. Por el contrario, tanto más es representación de la autoridad de Dios, de la autoridad de Cristo, cuanto más es solo un indicador, una mano 
que apunta afuera de sí misma hacia al Otro más grande. "Ni se llamen jefes, porque solo tienen un jefe que es el Mesías" (Mt 23, 10). El dedo indicador extremadamente largo de Juan Bautista que apunta al Cristo crucificado en el altar de Mathias Grünewald puede ser el símbolo de tal representación: "Yo no lo soy. (...) Yo no soy el Cristo" (Jn 1, 20-21).

Toda "representación" de la autoridad de Dios queda sometida a la "prohibición de imágenes": "No te harás una imagen, figura alguna de lo que hay arriba en el cielo, abajo en la tierra o en el agua bajo tierra. No te inclinarás ante ninguna imagen, ni las honrarás; porque yo soy Yahvé, tu Dios, fuerte y celoso" (Ex 20,4-5). La tarea más noble de la autoridad espiritual es mantener libre, con vigor, el espacio que únicamente corresponde a Dios.

En la tradición judía se encuentra la metáfora de la silla vacía. En el Séder, en la comida de la noche del Pésaj, se deja en la mesa una silla más para el profeta Elías, para expresar la esperanza de que vuelva con el Mesías. Agnes Heller, una filósofa de origen judío-húngaro, que escapó de la maquinaria mortal de los nazis, interpreta esa metáfora de una manera genial:

La silla vacía espera al Mesías. Si alguien la ocupa, podemos estar seguros de que se trata de un mesías pervertido o falso. Si alguien se lleva la silla, todo se acaba y el espíritu abandona la comunidad. La política no puede usar esa silla desocupada; pero en tanto se la deja estar donde estaba, justamente en el centro de la estancia, donde sigue inmóvil con su vacío amonestador y puede que incluso patético, los actores políticos tendrán que seguir contando con su existencia. Como mínimo, son libres de contar con su existencia. Todo el resto es pragmatismo. ${ }^{3}$

$\mathrm{Si}$ eso es válido como exigencia a cualquier ejercicio del poder político, mucho más válido lo es para cualquier ejercicio de autoridad espiritual. No permite ninguna "entronización", pues quien se sienta en la silla, la profana; la autoridad en la Iglesia solamente es legítima en la medida en que mantiene vacío el espacio que no le corresponde.

\section{3. "La terrible banalidad del mal", en nombre de la obediencia}

Hablar de obediencia en un mundo que pasó por la crítica de la Ilustración resulta un asunto sumamente difícil. "La Ilustración es la salida del hombre de su autoculpable minoría de edad", resuena el lema de Immanuel Kant. En un mundo postilustrado, renunciar a la autodeterminación no es ya considerado como una virtud, sino más bien como una cobardía de quien no se atreve a asumir la responsabilidad del actuar propio, en último término como una conducta inmoral. Dejarse llevar por los criterios y la voluntad de otros sin examinarlos

3. Según J. B. Metz, Dios y tiempo. Nueva teología política, Madrid, 2002, pp. 220 y s. 
parece alienante y deshumanizante. Además, resulta no solamente difícil, sino casi imposible hablar de la obediencia -incluso de la obediencia religiosadespués de los grandes sistemas fascistas y totalitaristas del siglo XX.

En 1961 la filósofa judío-alemana Hannah Arendt asistió como reportera en Jerusalén al proceso de Adolf Eichmann, organizador del transporte de millones de judíos a los campos de exterminio. Su descubrimiento más horroroso fue "la terrible banalidad del mal". Este hombre, que llevó a miles de seres humanos a una muerte espantosa, carecía de cualquier motivación, así como no había en él algún tipo de grandiosidad en su perversión. Eichmann fue simplemente un burócrata, cometió crímenes de "asesinato administrativo en masa" con la conciencia tranquila de que realizaba actos exigidos por su deber, de que actuaba por obediencia a "órdenes superiores". La sumisión a la autoridad se reveló como instrumento de la barbarie ${ }^{4}$.

En el relato de Arendt es penoso leer cómo Eichmann, en su propia defensa, exaltaba la "obediencia ciega" y la "obediencia de los cadáveres" - eco pervertido de las Constituciones de la Compañía de Jesús ${ }^{5}$ - . Los verdugos nazis, así como la mayoría de los verdugos de todas las dictaduras militares y regímenes totalitarios de siglo XX, se disculparon porque actuaban por "obediencia debida". Desde entonces, la palabra "obediencia" parece definitivamente manchada y desgastada.

Teniendo en cuenta todo esto, ¿se puede todavía rescatar la obediencia como concepto de la vida religiosa - de la vida religiosa renovada, según el Concilio Vaticano II-? Obviamente hay que recordar que Ignacio de Loyola - en sintonía con toda la tradición de la vida religiosa- pone la obediencia bajo una condición esencial: se trata de oír la voz del superior, "como si de Cristo nuestro Señor procediese", "en donde no exista con evidencia pecado alguno" y "en todo aquello a lo que puede extenderse la obediencia" ${ }^{\circ}$. Ignacio de ningún modo suspende la responsabilidad individual, no niega la dignidad de la conciencia de cada persona ni acepta la entrega al albedrío de un superior. Sin embargo, no basta afirmar esto si nos ponemos honradamente ante una justa crítica.

El voto de obediencia, la obediencia religiosa, en definitiva solo puede dirigirse hacia la autoridad de Dios. En lenguaje tradicional, cumplir la voluntad de Dios es la única motivación legítima de la obediencia religiosa. Precisamente

4. Cfr. H. Arendt, Eichmann en Jerusalén. Un estudio sobre la banalidad del mal, Barcelona, 1999.

5. "Negando con obediencia ciega todo nuestro parecer y juicio contrario en todo lo que el Superior ordena. (...) Cada uno de los que viven bajo obediencia se debe dejar llevar y regir de la divina Providencia por medio del Superior, como si fuese un cuerpo muerto"; en Constituciones, op. cit., n. 547.

6. Ibid., números 547 y 549. 
por eso, los verdaderamente obedientes son los verdaderamente libres, y son peligrosos para los poderosos. Se saben comprometidos incondicionalmente a la autoridad última y por eso están libres de todo servilismo. Aun arriesgando su propia vida tienen el valor de enfrentar cualquier instancia penúltima, están libres para mirar en profundidad y caminar erguidos tras las huellas de Jesús.

La pregunta decisiva es entonces: ¿cómo encontramos la voluntad de Dios en el día a día de nuestra vida concreta, sin engañarnos y sin caer en el infantilismo? ¿Dónde nos habla Dios de manera "infalible"? ¿Nos queda solo, en definitiva, proteger "la silla vacía" que nos remite al misterio trascendente $-\mathrm{y}$ así, al mismo tiempo, proteger la conciencia individual - ? ¿O aparece de pronto una verdadera mediación, una "presencia real", un "sacramento" de la autoridad última, "materializado" de manera real y concreta en este mundo, que con pleno derecho puede exigir $-\mathrm{y}$ merecer- nuestra obediencia incondicional?

\section{La autoridad de los que sufren}

"Solo conozco una autoridad que no puede ser revocada ni por la Ilustración ni por emancipación alguna: la autoridad de los que sufren"7. Así lo dice el teólogo alemán Johann Baptist Metz, en una conversación con el sobreviviente de la shoah y premio nobel de la Paz, Elie Wiesel.

La autoridad de Dios ciertamente no se hace presente como apoteosis en las manifestaciones del poder - ni del poder político ni del poder sacral-, sino "sub specie contrarii", en eso que parece ser su contrario. Toda la autoridad plena de Dios está realmente presente, tiene cuerpo y visibilidad, en los más vulnerables, en los sin poder, en las víctimas. Jesús mismo en su famosa parábola sobre el juicio final (Mateo 25) coloca la totalidad de la historia de la humanidad bajo la "autoridad de los que sufren". Su autoridad es la única en que se puede manifestar la autoridad de un Dios juez para todos los seres humanos - en todo el mundo de todos los tiempos-. Lo que llamamos la voz de la conciencia es nuestra reacción al ser visitados por ese sufrimiento ajeno ${ }^{8}$.

El sistema político dominante, la democracia liberal, es un concepto enfáticamente concentrado en la "igualdad" de todos los seres humanos. En consecuencia, con buena o mala intención muchas veces finge un mundo fantasma, la ilusión de un mundo igualitario sin sufrimiento en el que todos tengan las mismas oportunidades. Pero esa ficción no tiene nada que ver con nuestro mundo real. Exactamente porque nuestro mundo es un escándalo de desigualdad y de injusticia, la "parcialidad" de Dios a favor de las víctimas, de los marginados y excluidos necesita una "representación" en la historia concreta. "La Iglesia

7. J. B. Metz y E. Wiesel, A pesar de todo, Madrid, 1996, p. 42.

8. Cfr. J. B. Metz, Dios y tiempo, op. cit., pp. 228 y s. 
no existe para representar el poder político, sino para traer a la memoria la impotencia política"9. Esa es, en definitiva, la legitimación más honda de toda autoridad en la Iglesia.

Los que mueren de hambre o por causa de la violencia como consecuencia de una desigualdad escandalosa, los migrantes, combatidos por Europa y Estados Unidos en sus fronteras del sur, los presos políticos, en fin, todas las víctimas, todos ellos representan la autoridad máxima a la cual tenemos que responder sin rechistar. Ninguna instancia, tampoco la más alta institución jerárquica de la Iglesia, está por encima de esta autoridad. Una obediencia y un amor adulto a la Iglesia saben que esta es la vocación más noble de la vida religiosa, el servicio que debemos de verdad a la Iglesia: someternos a la autoridad de las víctimas y reclamar proféticamente que toda la Iglesia tiene que configurarse y definirse desde esta autoridad. Si no hace esto, está deformando el rostro de Jesucristo.

\section{¿Cómo vivir el voto de obediencia de cara a la "autoridad de los que sufren"?}

En el fondo, la "obediencia ciega" - en el sentido corrompido- es una actitud cómoda e indigna de una conducta adulta: acogerse al mandamiento de otro, llevar a cabo una orden y escapar así de la propia responsabilidad y de las consecuencias del propio actuar. También desde la "autoridad de los que sufren" surge una "orden" que nos compromete de manera incondicional y radical, pero de ninguna manera suspende la responsabilidad individual. Obedecer el mandato de las víctimas no infantiliza, sino al contrario exige un acto libre y adulto desde lo más hondo de cada persona. Es este acto el que nos hace personas humanas de verdad.

Vivir nuestro voto de obediencia bajo la autoridad de los que sufren es un proceso complejo con múltiples dimensiones: personales y comunitarias, místicas y políticas. Sin embargo, todo comienza con algo sencillo y elemental: despertar de nuestro narcisismo y nuestro mundo autorreferencial, y abrir los ojos y el corazón al sufrimiento del otro ser humano. Lo decisivo es resistir a la tentación de mirar hacia otro lado o refugiarse en la apatía. En la parábola del buen samaritano, Jesús cuenta cómo un hombre ha caído en manos de los ladrones que le robaron y golpearon. Un sacerdote y un levita ven al herido, pero tienen "intereses más importantes" que atender. No obstante, quien busca a Dios en el sentido de Jesús no conoce "intereses más importantes". Dios lo espera en el hermano o en la hermana maltrecha, y no va a encontrarlo en otro lado. El cristianismo no conoce otra mística que la de los "ojos abiertos".

¿Cómo responder entonces a esto que ven los ojos y siente el corazón frente a un ser humano que sufre? Con lo más sencillo y natural: atender las heridas, facilitar comida, hospedaje y ayuda económica. Hacer todo eso, de ninguna

9. Ibid., p. 219. 
manera es un acto de generosidad, sino que así obedecemos de modo elemental a la autoridad de los que sufren. No hace falta un largo proceso de discernimiento para decidir qué hay que hacer. Más bien eso se impone con evidencia inequívoca a cada persona íntegra. Esa experiencia corresponde a eso que Ignacio de Loyola llama "el primer tiempo para hacer una buena y sana elección": la voluntad de Dios se revela de manera inmediata y abrumadora. "Sin dubitar ni poder dubitar", hay que hacer lo que se impone ${ }^{10}$, de lo contrario sería desobediencia manifiesta. Con las palabras de un filósofo moderno: "Mira con atención y sabrás"11.

Ya es mucho si obedecemos cabalmente en tales situaciones que nos exigen de modo manifiesto y claro. Pero sabemos muy bien que muchas veces la vida es mucho más confusa y ambigua. Primero, porque no siempre es tan obvio cuáles son en verdad las medidas que favorecen la vida de la otra persona. Y segundo, porque la mayoría de las veces los malhechores no son algunos ladrones sueltos, sino que ganan su verdadera fuerza como parte de las "redes del mal": sean estas redes el crimen organizado, los narcos, los traficantes de personas y de órganos, o la política neoliberal y la codicia de petróleo y "tierras raras".

Además surge la pregunta difícil y perturbadora: ¿cómo se puede trasladar el mensaje de la parábola del buen samaritano al contexto de un mundo globalizado? Hoy no es uno el que ha caído en manos de los bandidos, sino que es una parte decisiva de la humanidad la que está a merced de ellos. Aquí sí se exige un discernimiento serio y profundo para saber cómo defender las vidas de las víctimas frente a esta amenaza masiva. Obedecer a la "autoridad de los que sufren" exige en esta dimensión todo nuestro conocimiento y toda nuestra ciencia; exige toda nuestra creatividad y fantasía para inventar con eficiencia espacios que hagan florecer la vida en este mundo real, desfigurado por el pecado y por las estructuras del pecado.

Todavía tiene valor lo que Dietrich Bonhoeffer, el gran mártir de la Iglesia luterana alemana, dijo en su contexto histórico: ya no es suficiente "atender a las víctimas bajo la rueda", sino que se nos exige "bloquear los radios para parar la rueda"12. En esta dimensión la misericordia y el amor apasionado tienen que realizarse en estrategias bien pensadas. Con la astucia del Evangelio, como congregaciones religiosas, podemos aprovechar nuestra ventaja como uno de los primeros "global players" en la historia humana y usar nuestras redes internacionales -en la propia congregación, en interconexión con otras congregaciones

10. Cfr. I. de Loyola, Ejercicios espirituales, n. 175.

11. Hans Jonas, según J. B. Metz, Memoria passionis. Una evocación provocadora en una sociedad pluralista, Santander, 2007, p. 167.

12. $C f r$. D. Bonhoeffer, $D B W 14$, p. 421. 
y relacionándonos con todos y todas los que luchan por la humanización del planeta-.

El discernimiento como respuesta a la "autoridad de los que sufren" $-\mathrm{y}$ así realizar nuestro voto de obediencia- es una tarea permanente y exigente. Es tarea que exige la entrega de cada persona en su ser más íntimo y es tarea que exige el compromiso comunitario constante y tenaz. En lo fundamental es un ejercicio de "contemplación"; un ejercicio de mirar y escuchar con atención y honradez, para que "la autoridad de las víctimas", el "sacramento de la voluntad de Dios", nos hable. Hace falta un corazón que escuche con paciencia para entender lo que las víctimas demandan concretamente de nosotros en la situación.

Si tomamos en serio este concepto de obediencia bajo la autoridad de los que sufren, ¿qué puede significar todavía el rol de una superiora en una comunidad religiosa? ¿Está en definitiva de sobra? Ciertamente no, pero en un esfuerzo riguroso hay que repensar su función desde las raíces de la vida religiosa. No hay duda de que también las superioras están bajo la "autoridad de los que sufren" y comprometidas con ella. Sin embargo, exactamente por eso la autoridad de las superioras es más necesaria que nunca. Su tarea más noble es vigilar con diligencia que toda la comunidad se ponga bajo la única representación legítima de la autoridad de Dios en un proceso continuo. Su rol es animar y reclamar con vigor el discernimiento, pero más que todo empujar a que toda la comunidad se ponga en marcha de modo "presto y diligente"13: que busque la cercanía física con los pobres y excluidos, comparta con ellos y ellas la vida y sus aflicciones, aprenda su lenguaje, y busque y goce su amistad. En consonancia con esto, debemos reconocer que da una enorme esperanza y nos abre una brecha que el papa Francisco defina su ministerio exactamente de esta manera, cuando nos dice: "La Iglesia está llamada a salir de sí misma e ir hacia las periferias, no solo las geográficas, sino también las periferias existenciales: las del misterio del pecado, las del dolor, las de la injusticia, las de la ignorancia y prescindencia religiosa, las del pensamiento, las de toda miseria".

Si nos ponemos con decisión bajo la "autoridad de los que sufren", iremos hacia una renovación profundamente jesuánica de la vida religiosa, hacia una vida auténtica y fecunda según los consejos evangélicos. De este modo, nuestros hermanos y hermanas más vulnerables se convertirán en nuestros verdaderos maestros y guías hacia el misterio de Dios.

13. I. de Loyola, Ejercicios, op. cit., n. ${ }^{\circ} 91$. 